\title{
A RELIGIÃO ENTRE ESTUdANTES DE CIÊNCIAS SOCIAIS HOJE: DECLÍNIO DO ATEÍSMO OU DESPOLARIZAÇÃO DE POSICIONAMENTOS?
}

Airton Luiz Jungblut

Apreciar dados atuais sobre as crenças (e descrenças) religiosas entre alunos graduandos de Ciências Sociais não deixa de ser instigante para quem, como eu, não faz tanto tempo esteve situado entre o público alvo desta pesquisa. Pois é me valendo dessa quase dupla perspectiva público alvo/ analisador que pretendo aqui, a título de contribuição, comentar ensaisticamente alguns aspectos dessa pesquisa, particularmente aqueles referentes à PUCRS. Faço isso não só por ser esta a Universidade onde leciono atualmente e onde coordenei a aplicação dessa pesquisa ${ }^{1}$, mas sobretudo por ali ter vivido, durante a década de 80 , a situação de aluno graduando de Ciências Sociais. Não sendo essa experiência tão longínqua no tempo, posso compor um quadro que pode ser comparado aos dados atuais, um pouco ao estilo daquele apresentado por Regina Novaes em seu artigo sobre pesquisa similar a essa realizada no início da década de noventa. Reconheço, também, como essa autora, os limites que lembranças pessoais possuem, já que construídas sempre seletivamente. Assim sendo, tentarei dar a elas tão-somente a importância que damos aos relatos orais quando fazemos antropologia.

Professor junto ao Departamento de Ciências Sociais da Faculdade de Filosofia e Ciências Humanas da PUCRS

${ }^{1}$ Agradecimentos a Sueli da Rosa Gomes, bolsista graduanda em Ciências Sociais, que aplicou os questionários, e à professora Jacqueline Britto Pólvora, que auxiliou na coordenação da pesquisa.

Debates do NER, Porto Alegre, ano 2, n. 2, p. 133-143, agosto de 2001 
Minhas memórias a respeito das crenças (e descrenças) religiosas de meus colegas graduandos em Ciências Sociais na PUCRS dos anos 80 compõem um quadro um tanto diverso daquele descrito por Regina Novaes nos anos 70 para os estudantes cariocas do mesmo curso e que serve de contraponto em sua análise para pesquisa similar a essa realizada nos anos 90 .

Regina Novaes relata que, nos anos 70, “seja pela via dos pressupostos do materialismo histórico, seja através dos óculos do relativismo antropológico", a religião dos estudantes do IFCS (do "Largo do S. Francisco") assumia uma certa invisibilidade, ou fazia parte do "indizivel" daquelas pessoas. Percebo que entre meus colegas, nos anos 80 , a situação era um tanto diversa, porque mesmo tendo em vista também os pressupostos do materialismo histórico - e, com menos importância na PUCRS da época, o relativismo antropológico - ao invés da religião estar invisibilizada nos discursos desses, era, ao contrário, freqü entemente tematizada em sua inaceitabilidade como "ópio do povo", como "mecanismo de dominação ideológica das classes populares", etc.. Ou seja, talvez por tratar-se de um outro contexto, a religião não era algo invisível nos discursos destes meus colegas nos anos 80.

Vivia-se, como se sabe, um período de grande politização nos círculos universitários brasileiros, pois estava em marcha o processo de redemocratização do país. Parecia que, finalmente, seria possível retomar as lutas sociais interrompidas pelo regime militar, e essa sensação enchia de entusiasmo e sonhos uma geração de universitários que se espelhava no mítico engajamento político das gerações anteriores. Certamente por essa razão, os cursos de Ciências Sociais tinham grande procura naquela época, pois era através deles que muitos buscavam se instruir sobre os saberes que auxiliariam a pensar as transformações sociais sonhadas. As Ciências Sociais ajudavam na construção identitária daqueles jovens ávidos por se tornarem "esquerdistas" e se 
engajarem nas lutas pelas transformações que a sociedade brasileira estaria a exigir. Contudo, percebo agora que muitos dos meus colegas certamente buscavam as Ciências Sociais por razões muito próximas daquelas que animam os modismos de épocas. Desconfio que, para muitos, mais importante do que dominar os conteúdos ministrados nas disciplinas do curso era apossar-se de algumas retóricas e de alguns sinais diacríticos próprios da identidade "militante de esquerda esclarecida”, tão caros naquela época. Nesse processo de construção identitária, era fundamental dominar ao menos rudimentos do discurso marxista. Desse corpo discursivo é que certamente saíam a maior parte dos posicionamentos que compunham a tão almejada identidade de "militante esquerdista intelectualizado".

Dentre esses posicionamentos identitários, figurava com algum destaque o "ateísmo" e/ou a crença de que a religião era tão-somente um importante instrumento de dominação ideológica para a perpetuação do modo de produção capitalista. Assim, para muitos de meus colegas, não havia nada mais eficiente do ponto de vista identitário em relação a religião do que simplesmente se dizer "ateu", e isso adquiria ainda maior importância simbólica em se tratando de ser dito dentro de uma universidade confessional católica. Havia, é claro, por parte de uns poucos, algumas transigências para com formas de religião consideradas alternativas às modalidades dominantes, como, por exemplo, algumas simpatias por parte de alguns alunos pelas religiões afro-brasileiras e pelos ensinamentos do guru indiano Bhagwan Rajneesh. Também havia alguma simpatia pela ala esquerdista da Igreja Católica animada pela celebrada "Teologia da Libertação", mas, neste caso, sempre com as ressalvas de que se tratava de uma forma de engajamento militante qualitativamente inferior, "a nivel de consciência", ao materialismo marxista.

Assim, naqueles anos, em relação à religião, o que tinha grande atratividade como sinal de identificação frente ao 
conjunto geral de traços identitários valorizados por essa subcultura universitário-esquerdista era, inegavelmente, o "ateísmo" e esta opção identitária. Embora não tenhamos isso comprovado por pesquisas, me parece ter sido largamente majoritária entre aqueles estudantes de Ciências Sociais. Evidentemente, há de se supor que entre o que era manifestado nos discursos e o que eles realmente sentiam em relação à religião podia haver uma defasagem em benefício de outras opções que não o ateísmo. Estas sim, poderíamos dizer, permaneceram escondidas, indiziveis.

Nos dias atuais, se formos atentar para os dados da pesquisa alvo das análises que aqui estamos a empreender, teríamos que admitir que o ateísmo deixou claramente de ser atrativo como opção identitária entre os estudantes de Ciências Sociais da PUCRS. No caso da PUCRS, temos apenas $6,3 \%$ de alunos que se definem como ateus, índice apenas superior à também confessional católica UNISINOS (4,2\%). De um modo geral, a primeira coisa que me chama a atenção na pesquisa, e sobre a qual eu gostaria de me deter, são esses números, ao meu ver surpreendentemente baixos para a opção "ateu" quando a pergunta é "Você se definiria como?" (tabela 6).

Considerado isoladamente, esse dado poderia nos levar a supor que essa opção não é mais tão valiosa como outrora como sinal diacrítico entre os alunos de Ciências Sociais da PUCRS. Muito provavelmente poderíamos ponderar que isso se deve a um processo complexo que combina uma série de transformações ocorridas nestes últimos quinze anos, tais como: decadência do marxismo como utopia global e como paradigma dentro das Ciências Sociais; despolitização da sociedade brasileira, de um modo geral, e da subcultura universitária, de um modo particular; mudança do perfil dos alunos dos cursos de Ciências Sociais, etc. Talvez, derrubado o muro de Berlim, e consolidada a redemocratização política no Brasil, o marxismo tenha deixado de ser o maior fornecedor do kit identitário padrão do aluno de Ciências So- 
ciais, e, com isso, o ateísmo, decaído enquanto sinal diacrítico atraente para esses estudantes, tenha aparentemente diminuído enquanto opção diante da religião.

No entanto, olhando com mais atenção, percebe-se que o declínio do ateísmo como opção identitária diante da religião não significa simplesmente que haja a inflação de uma opção claramente oposta a essa, de uma opção propriamente "teísta". Se observarmos as outras opções que compõem a tabela 6 (veja a seguir) veremos que 16,7\% se dizem agnósticos e $14,6 \%$ se dizem sem religião. Ora, trata-se de opções identitárias em relação à religião, em que a crença em Deus não chega a ser algo dado como certo, no primeiro caso, ou capaz de levar o indivíduo a confessar a doutrina religiosa e/ou se integrar à congregação que a rotinize, no segundo caso. O que quero dizer é que os números referentes tanto à opção "agnóstico" como à opção "sem religião" demonstram a existência de um grupo considerável de pessoas que, embora não se definam como atéias, não assumem posicionamentos e/ou adotam práticas que poderíamos considerar como tradicionalmente "teístas". No caso do agnosticismo isso é patente, pois se trata de uma declaração de reconhecimento da impossibilidade de dar resposta satisfatória à questão da existência ou inexistência de Deus: nem crença nem descrença. O agnosticismo é, digamos, uma opção "em cima do muro" que separa o teísmo do ateísmo. Os agnósticos costumam dizer que são mais racionais que os ateus, pois, ao contrário desses, não afirmam categoricamente algo que, segundo dizem, não pôde ainda ser provado: a inexistência de Deus. 
Tabela 6 - "V ocê se identificaria como?" por Curso de Graduação

\begin{tabular}{lccccc}
\hline & \multicolumn{5}{c}{ Voc ê se identificaria com o? (\%) } \\
\cline { 2 - 6 } Unive rsidade & Re ligioso & Sem religião & Agnóstico & Ateu & Total \\
\hline UFRGS DN & 29,7 & 28,4 & 21,6 & 20,3 & 100,0 \\
UFRGS NT & 41,5 & 26,4 & 15,1 & 17,0 & 100,0 \\
UNISINOS & 77,5 & 15,5 & 2,8 & 4,2 & 100,0 \\
UFM G & 55,8 & 24,2 & 10,5 & 9,5 & 100,0 \\
P UC - RS & 62,5 & 14,6 & 16,7 & 6,3 & 100,0 \\
UFJF & 56,3 & 18,3 & 16,9 & 8,5 & 100,0 \\
UFRJ & 32,0 & 39,9 & 19,0 & 9,2 & 100,0 \\
Média da col una & 48,0 & 26,5 & 15,0 & 10,4 & 100,0 \\
\hline
\end{tabular}

No caso dos "sem religião", notando que seu crescimento tem sido percebido como um fenômeno generalizado na sociedade brasileira, compartilho da opinião de Alexandre Brasil Fonseca, de que se trata de algo intimamente associado ao chamado processo de secularização que inegavelmente - não desconsiderando, é claro, os atuais surtos de reavivamento religioso - está em marcha. Concordo com esse autor quando diz:

"Encontra-se pujante no seio da sociedade brasileira um processo de secularização, que tem dois movimentos. O lento e gradual estabelecimento de uma visão de mundo ausente da noção religiosa, o que ainda tomará um longo tempo, e a definição dos indivíduos em direção a auto afirmação e compreensão de que podem viver 'sem religião'. O que não precisa ser necessariamente lido como uma negação de Deus, mas que deve ser interpretado como diminuição da religião-de-Igreja e da interferência da religião no Estado.” (Fonseca, 1998: 12) 
Os "sem religião", aceitando essas considerações, estão, portanto, muito mais para uma opção de "fuga da religião" do que de "fuga do ateísmo". Um "sem religião" é, na prática, alguém muito mais próximo de um ateu em seu desapego às coisas da religião, do que de um teísta tradicional em sua ostentada fé em Deus. No caso da PUCRS, há então que se considerar que essa situação verificada entre seus alunos de Ciências Sociais talvez esteja muito mais relacionada a tendências que extrapolam a subcultura universitária do que propriamente a uma resposta às transformações nas demandas identitárias desse grupo.

Indo além, é ainda possivel encontrar, mesmo entre os que se dizem "religiosos", uma parcela importante de potenciais "sem religião", e, conseqüentemente, de pessoas que distam de um padrão tradicional "teísta". Vejamos o que nos mostram as tabelas 7 e 8 :

Tabela 7 - "Você tem religião?" por Curso de Graduação

\begin{tabular}{llcl}
\hline & \multicolumn{3}{c}{ Você tem religião? (\%) } \\
\cline { 2 - 4 } Universidade & Sim & Não & Total \\
\hline UFRGS DN & 35,1 & 64,9 & 100,0 \\
UFRGS NT & 53,7 & 46,3 & 100,0 \\
UNISINOS & 78,1 & 21,9 & 100,0 \\
UFMG & 57,7 & 42,3 & 100,0 \\
PUC - RS & 67,3 & 32,7 & 100,0 \\
UFJF & 59,7 & 40,3 & 100,0 \\
UFRJ & 34,7 & 65,3 & 100,0 \\
M édia da coluna & 52,0 & 48,0 & 100,0 \\
\hline
\end{tabular}


Tab ela 8 - Religião do entrevistado por Curso de Gra duação

\begin{tabular}{lcccccc}
\hline & \multicolumn{5}{c}{ Religião do entrevistado (\%) } \\
\cline { 2 - 7 } Universidade & $\begin{array}{c}\text { Católicanão- } \\
\text { praticante }\end{array}$ & $\begin{array}{c}\text { Católica } \\
\text { praticante }\end{array}$ & Espíita & Protestante Pentecostal & Outn $^{3}$ \\
\hline UFRGS DN & 27,6 & 1,3 & 6,6 & 3,9 & 1,3 & 6,3 \\
UFRGS NT & 31,5 & 5,6 & 16,7 & - & - & 6,2 \\
UNISINOS & 31,1 & 24,3 & 10,8 & 9,5 & 8,1 & 5,4 \\
UFM G & 23,5 & 18,4 & 8,2 & 9,2 & - & 4,0 \\
PUC - RS & 34,7 & 14,3 & 14,3 & - & 2,0 & 2,0 \\
UFJF & 12,5 & 26,4 & 11,1 & 8,3 & 2,8 & 8,4 \\
UFRJ & 9,8 & 5,9 & 7,2 & 3,9 & 2,0 & 8,9 \\
M édia da coluna & 21,7 & 13,0 & 9,7 & 5,4 & 2,3 & 6,3 \\
\hline
\end{tabular}

Na tabela 7, vemos que na PUCRS 67,3\% dizem que têm religião. A tabela 8 nos mostra como se dividem entre distintas modalidades religiosas esses $67,3 \%$ que disseram que sim, que têm uma religião. Reparem, primeiramente, que esse número de $67,3 \%$ dos que dizem que "sim" (têm uma religião) na tabela 7 é 4,8 pontos inferior aos que se disseram "religiosos" na tabela 6. Essa diferença demonstra, no mínimo, que há uma certa dificuldade entre o público-alvo de auto-enquadrar-se nas categorias fornecidas pela pesquisa, pois uma ligeira troca de termos, de ser religioso para ter religião, já altera os resultados em 4,8. Acredito que, mais do que demonstrar uma confusão interpretativa dos entrevistados ou uma falta de coerência interna no conjunto de suas respostas, isso nos informa sobre as dúvidas autoclassificatórias que habitam as mentes não só destes

\footnotetext{
${ }^{2}$ Relativas ao total de entrevistados por curso. Não há coluna total, haja vista que a questão era de múltipla escolha.

3 Afro-brasileira, Oriental, Judaica e Outra Indefinida somadas. Nessas categorias, em nenhum dos casos a porcentagem superou 3\%. Coluna apenas ilustrativa, pois podem acontecer escolhas múltiplas envolvendo duas ou mais das categorias que aqui foram somadas.
} 
estudantes, mas de muitas pessoas na atualidade.

Indo adiante, se observarmos melhor os dados da tabela 8 veremos que entre os $67,3 \%$ dos entrevistados que dizem ter uma religião, há $34,7 \%$ de católicos que se enquadram na categoria "não-praticantes". Ora, mais da metade dos que poderiam ser considerados "teístas" tradicionais (que não colocariam em questão a existência de Deus como os "agnósticos" e muitos "sem religião", por exemplo) são, na verdade, pessoas que não praticam a religião com a qual se dizem identificados. Essa opção identitária, bem se sabe, é a grande categoria inclusiva da sociedade brasileira em se tratando de religião, pois dentro dela pode ser disposta grande parte da população brasileira, inclusive, dependendo dos cálculos autoclassificatórios de cada um, muitos agnósticos, sem religião, afro-brasileiros, etc. Na verdade, quando muitas pessoas estão a dizer que são católicos "não-praticantes", estão simplesmente fazendo uma declaração de pertencimento a uma categoria, bastante próxima daquela feita pelos "sem religião". Estão se utilizando de uma "identidade sacramental" (MARIZ \& MACHADO, 1994: 28) através da qual se protegem de eventuais estigmas que a não-crença em qualquer uma de suas modalidades (materialista, ateu, agnóstico, sem religião, etc) possa provocar. Desconfio que muitos dos católicos não-praticantes, ao menos os da Ciências Sociais da PUCRS, se esclarecidos sobre o que significa ser um "sem religião", poderiam tranqüilamente aceitar essa segunda classificação.

Assim, feitos os cálculos, entre os entrevistados que possam com alguma segurança ser considerados efetivamente "teístas", há somente $32,6 \%(14,3 \%$ católicos praticantes, $14,3 \%$ espíritas, $2,0 \%$ pentecostais, $2,0 \%$ outros).

O que esses dados trazem à tona é que, se há uma surpreendente queda do ateísmo entre os estudantes de Ciências Sociais da PUCRS em comparação a um quadro de cerca de quinze anos atrás (infelizmente não captado por pesquisa), isso não foi em proveito, propriamente, do crescimento 
de um "teísmo" mais tradicional. O que efetivamente parece ter havido é que, mais despolitizados do que meus colegas do anos 80, os atuais alunos do curso de Ciências Sociais da PUCRS (e, certamente, a sociedade em geral) parecem dispor de um número maior de possibilidades identitárias em relação à religião do que o existente anteriormente. O ateísmo como sinal diacrítico fornecido pelo kit marxista, passou a concorrer com outras modalidades identitárias talvez com maior capacidade de traduzir fielmente as gradações entre crença e descrença religiosa e que se manifestam nas percepções desses estudantes. Mas se isso ocorre, minguando a expressividade atéia, não me parece que foi porque tenha havido uma "vingança dos deuses", um retrocesso no processo de secularização ou coisa que o valha. O que ocorreu de fato foi uma pluralização das opções. Com a quebra do monopólio do ateísmo, enfraqueceu-se uma descontinuidade entre a crença e descrença religiosa. Assim, se fôssemos sobrepor, arbitrariamente, é claro, as dicotomias esquerda/ direita e ateísmo/teísmo, poderíamos dizer que surgiu entre esses dois pólos um ateísmo de direita, representado pelos agnósticos, e um teísmo de esquerda, representado pelos sem religião.

Para concluir, se esse meu ensaio inter pretativo tiver alguma chance de estar correto, pressinto que doravante, em pesquisas dessa natureza, teremos que cada vez mais prestar atenção às sutilezas que separam as categorias classificatórias efetivamente importantes. No momento da confecção de nossos instrumentos de pesquisa, deveremos, talvez, levar em conta muito mais as continuidades do que as descontinuidades entre diferentes tipos de opções religiosas. Afinal, como demonstrou Colin Campbell, pode fazer bastante diferença nos resultados de uma pesquisa sobre religião se perguntamos a alguém se acredita em Deus ou se acredita em "algum tipo de espírito ou força vital" (1997: 10). 


\section{Referências Bibliogáficas}

CAMPBELL, Colin. "A orientalização do Ocidente: reflexões sobre uma nova teodicéia para um novo milênio." Religião $e$ Sociedade, v. 18, n.1, 1987.

FONSECA, Alexandre Brasil. "Nova Era evangélica, Confissão Positiva e o crescimento dos sem religião". Trabalho apresentado nas VIII Jornadas sobre Alternativas Religiosas na América Latina, São Paulo, 22 a 25 de setembro de 1998.

MARIZ, Cecília \& MACHADO, Maria das Dores. "Sincretismo e trânsito religioso: comparando carismáticos e pentecostais". Comunicações do ISER, n. 45, 1994.

NOVAES, Regina.Religião e política: sincretismos entre alunos de ciências sociais. Comunicações do ISER, n. 45, ano 13, p. 68, Rio de Janeiro, 1994. 